\title{
Perioperative approach to precapillary pulmonary hypertension in non-cardiac non-obstetric surgery
}

\author{
Debabrata Bandyopadhyay $\mathbb{1}^{1}$, Christopher Lai $\mathbb{1}^{2,3,4}$, Juan N. Pulido ${ }^{5}$, Ricardo Restrepo-Jaramillo ${ }^{1}$, \\ Adriano R. Tonelli, ${ }^{6,7}$ and Marc Humbert $\mathbb{1}^{3,4,8}$
}

\begin{abstract}
${ }^{1}$ Center for Advanced Lung Disease and Lung Transplant, University of South Florida - Tampa General Hospital, Tampa, FL, USA. ${ }^{2}$ Faculté de Médecine, Université Paris-Saclay, Le Kremlin Bicêtre, France. ${ }^{3}$ Assistance Publique Hôpitaux de Paris, Service de médecine intensive - réanimation, Hôpital Bicêtre, DMU CORREVE, FHU SEPSIS, Groupe de recherche clinique CARMAS, Le Kremlin-Bicêtre, France. ${ }^{4}$ Inserm UMR_S 999, Hôpital Marie Lannelongue, Le Plessis Robinson, France. ${ }^{5}$ Dept of Anesthesiology and Critical Care Medicine, Swedish Medical Center, Seattle, WA, USA and US Anesthesia Partners - Washington, Seattle, WA, USA. ${ }^{6}$ Dept of Pulmonary, Allergy and Critical Care Medicine, Respiratory Institute, Cleveland Clinic, Cleveland, OH, USA. ${ }^{7}$ Pathobiology Division, Lerner Research Institute, Cleveland Clinic, OH, USA. ${ }^{8}$ Assistance Publique Hôpitaux de Paris, Service de Pneumologie et Soins Intensifs Respiratoires, Centre de Référence de l'Hypertension Pulmonaire, Hôpital Bicêtre, Le Kremlin-Bicêtre, France.
\end{abstract}

Corresponding author: Marc Humbert (marc.humbert@aphp.fr)

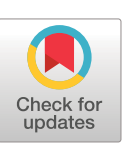

This version is distributed under the terms of the Creative Commons Attribution NonCommercial Licence 4.0. For commercial reproduction rights and permissions contact permissions@ersnet.org

This article has supplementary material available from err.ersjournals.com

Received: 11 July 2021 Accepted: 12 Aug 2021

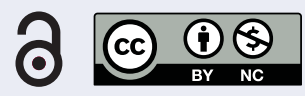

Shareable abstract (@ERSpublications)

$\mathrm{PH}$ confers substantial perioperative mortality and morbidity. Yet, satisfactory outcome is feasible by focusing on disease-adapted complex anesthesiologic management. It involves mitigation of factors that worsen right ventricular function. https://bit.ly/2W8Z4Ag

Cite this article as: Bandyopadhyay D, Lai C, Pulido JN, et al. Perioperative approach to precapillary pulmonary hypertension in non-cardiac non-obstetric surgery. Eur Respir Rev 2021; 30: 210166 [DOI: 10.1183/16000617.0166-2021].

\section{Abstract}

Pulmonary hypertension (PH) confers a significant challenge in perioperative care. It is associated with substantial morbidity and mortality. A considerable amount of information about management of patients with PH has emerged over the past decade. However, there is still a paucity of information to guide perioperative evaluation and management of these patients. Yet, a satisfactory outcome is feasible by focusing on elaborate disease-adapted anaesthetic management of this complex disease with a multidisciplinary approach. The cornerstone of the peri-anaesthetic management of patients with PH is preservation of right ventricular (RV) function with attention on maintaining RV preload, contractility and limiting increase in RV afterload at each stage of the patient's perioperative care. Pre-anaesthetic evaluation, choice of anaesthetic agents, proper fluid management, appropriate ventilation, correction of hypoxia, hypercarbia, acid-base balance and pain control are paramount in this regard. Essentially, the perioperative management of $\mathrm{PH}$ patients is intricate and multifaceted. Unfortunately, a comprehensive evidence-based guideline is lacking to navigate us through this complex process. We conducted a literature review on patients with $\mathrm{PH}$ with a focus on the perioperative evaluation and suggest management algorithms for these patients during non-cardiac, non-obstetric surgery.

\section{Introduction}

Pulmonary hypertension (PH) is defined as elevated mean pulmonary arterial pressure (mPAP) $>20 \mathrm{mmHg}$ at rest during a right heart catheterisation (RHC) [1]. Conceptually PH can be divided as "precapillary PH" due to pulmonary vascular disease, "postcapillary $\mathrm{PH}$ " due to pulmonary venous hypertension or combined pre- and postcapillary (Cpc-PH). Precapillary $\mathrm{PH}$ is characterised by remodelling of the pulmonary vasculature with high pulmonary vascular resistance (PVR) $\geqslant 3$ Wood units (WU) and normal pulmonary artery wedge pressure (PAWP) $\leqslant 15 \mathrm{mmHg}$ [1]. Precapillary PH remains a progressive disease, if untreated, leading to right ventricular (RV) dysfunction and death [2, 3]. However, recent major advances in treatment have increased life expectancy and PH patients often undergo surgical procedures.

Unfortunately, precapillary PH is still a major risk factor for perioperative complications. It yields perioperative haemodynamic perturbations that places additional stress on an already strained RV. This review highlights the pertinent pathophysiology and focuses on the perioperative management of 
precapillary $\mathrm{PH}$ condition, cognizant of the fact that the bulk of the literature focuses on patients with precapillary $\mathrm{PH}$.

\section{Classification of $\mathrm{PH}$}

The World Health Organization (WHO) classifies PH into five different groups (Supplementary table ST1), based on aetiology, pathophysiology, haemodynamic characteristics and management [1]. Pulmonary arterial hypertension (PAH) represents group $1 \mathrm{PH}$ and includes idiopathic, heritable, drug/toxin-induced, connective tissue disease, congenital heart disease, HIV, portal hypertension and schistosomiasis. Data from Europe suggest a yearly incidence of 2.5-7.0 and prevalence of 25-50 cases per million population. PAH patients are increasingly diagnosed in the older population [4]. Recent data from the US REVEAL registry (Registry to EValuate Early And Long-term PAH disease management) indicates a median age at diagnosis of $52 \pm 14$ years [5]. These patients are commonly treated with medications approved for PAH (Supplementary table ST2).

Group 2, the most common cause of PH [6], is due to left ventricular (LV) dysfunction and left-sided valvular heart diseases. This "postcapillary $\mathrm{PH}$ ” results from backward transmission of left heart filling pressures into the pulmonary capillary bed and venous system. Further characterisation of this condition is beyond the scope of the current review.

Group $3 \mathrm{PH}$ is due to chronic lung diseases and/or hypoxia. Elevated mPAP and PVR in these patients herald a poor prognosis. Physicians must be aware that pulmonary vasodilators approved for PAH can worsen the ventilation/perfusion $\left(V^{\prime} / Q^{\prime}\right)$ mismatch and consequent hypoxia in these patients. Inhaled treprostinil recently received United States Food and Drug Administration approval to treat $\mathrm{PH}$ associated with interstitial lung disease [7].

Group 4 PH results mostly from chronic thromboembolic pulmonary disease (CTEPH), but also from rare causes such as extramural obstruction from sarcomas or other tumours, arteritis and congenital pulmonary artery stenosis. A normal lung $V^{\prime} / Q^{\prime}$ scintigraphy effectively rules out CTEPH with a high degree of sensitivity [8]. Pulmonary endarterectomy partially or fully reverses this condition in selected patients. Balloon pulmonary angioplasty (BPA) is a percutaneous minimally invasive therapy in CTEPH, which improves oxygen requirement, pulmonary haemodynamics and exercise capacity [9]. Guanylate cyclase stimulator riociguat is the treatment of choice in inoperable or residual CTEPH after surgery [10].

Group $5 \mathrm{PH}$ consists of heterogeneous groups of diseases where the origin of $\mathrm{PH}$ is usually multifactorial and poorly understood. The use of pulmonary vasodilators depends on the aetiology of PH with most evidence originating from relatively small observational case series.

Precapillary PH can be noted in groups 1, 3, 4 and 5; postcapillary $\mathrm{PH}$ is observed in groups 2 and 5 and Cpc-PH [11].

The prognosis of $\mathrm{PH} / \mathrm{PAH}$ remains poor. Data from the REVEAL registry suggest that 1- and 5-year survival rates are $90.4 \%$ and $65.4 \%$, respectively, in PAH patients [12]. Poor prognostic factors of $\mathrm{PH}$ are WHO functional class III or IV (supplementary table ST3), occurrence of syncope, renal dysfunction, six-minute walk distance $(6 \mathrm{MWD})<165 \mathrm{~m}, \mathrm{RV}$ dysfunction, right atrial pressure (RAP) $\geqslant 14 \mathrm{mmHg}$, pericardial effusion and PVR $\geqslant 5$ WU. Recently, risk scores, a composite of functional status, exercise testing, biomarkers, echocardiographic parameters and haemodynamic status to predict 1-year survival, have gained popularity [11, 13]. In general, the degree of RV dysfunction is a major determinant for prognosis and survival of these patients.

\section{PAH medications}

The treatment of PAH has evolved over time with increased availability of many pulmonary vasodilators including calcium channel blockers (exclusively offered to the small subset of patients with an acute vasodilator response to inhaled nitric oxide (NO), endothelin receptor antagonists (ambrisentan, bosentan and macitentan), phosphodiesterase type-5 inhibitors (sildenafil and tadalafil), guanylate cyclase stimulator (riociguat), prostacyclin analogues (epoprostenol, iloprost and treprostinil) or prostacyclin receptor agonist (selexipag) (Supplementary table ST2). Recent studies support using upfront or a sequential combination of pulmonary vasodilators [14-16]. Diuretics are useful to reduce RV pre-load. Supplemental oxygen is prescribed to maintain arterial oxygen saturation $\left(S_{\mathrm{pO}_{2}}\right) \geqslant 92 \%$. Data regarding routine anticoagulation in PAH is inconclusive, with conflicting study results [17-19], while lifelong therapeutic anticoagulation is recommended in CTEPH [8]. 
Haemodynamic pathophysiology of $\mathrm{PH}$

The pulmonary circulation is a low resistance circuit. The prognosis and survival of patients with precapillary $\mathrm{PH}$ is associated with the ability of the RV to adapt to increased afterload. The RV is a crescent shaped, thin-walled, low-pressure system, allowing it to adapt to a moderate increase in its afterload by dilatating. Also, its reduced muscle mass and low afterload minimises oxygen demand as well as enabling coronary perfusion in both systole and diastole. Unlike the LV, RV stroke volume is overtly sensitive to acute change in afterload that could result in a marked reduction in RV stroke volume [20]. The haemodynamic consequences of precapillary $\mathrm{PH}$ depend upon complex interactions between pulmonary vasculature and RV (RV/pulmonary artery (PA) coupling).

Precapillary $\mathrm{PH}$ develops because of pulmonary arterial vasoconstriction, vascular inflammation and remodelling [21]. The consequent progressive elevation in PVR alters RV geometry and function [22]; in fact, the RV remodels (RV concentric hypertrophy) and dilates in response to a chronic elevation in pressure and PVR. This stage is associated with RV dysfunction with clinical implications [11]. Moreover, excessive RV dilatation can also impair the LV function, by displacing the interventricular septum to the left. This leftward shift of septum, in a fixed pericardial cavity, mechanically impacts the LV filling and outflow [23]. This phenomenon, known as ventricular interdependence, reduces LV filling during diastole with an additional reduction of CO in systole. Furthermore, the increase in mPAP and/or systemic hypotension decreases the pressure gradient between diastolic arterial pressure and RV pressure, reducing RV perfusion and leading to a risk of RV ischaemia [24]. Finally, coronary perfusion is the major determinant in RV compensation capacity [25]. Thus, PH patients with hypertrophied and dilated RV have a limited adaptive ability to respond to additional disturbance in RV afterload when exposed to acute decompensations [26], which is associated with a poor short-term prognosis. Finally, all these phenomena could lead to a decrease in $\mathrm{CO}$ and increased RV filling pressure with venous congestion, resulting in multi-organ dysfunction due to decreased perfusion pressure.

Anaesthesia in patients with $\mathrm{PH}$

Effect of PH in non-cardiac surgery

Anaesthetising $\mathrm{PH}$ patients portends considerable risks. Yet, the majority of the data assessing perioperative complications comes from small observational or retrospective studies. The average age at diagnosis of $\mathrm{PH}$ has increased and the availability of newer drugs has led to improved survival. Currently, $\mathrm{PH}$ patients tend to be older with multiple co-morbidities, many of which require surgical interventions.

The 2014 American College of Cardiology/American Heart Association guidelines on perioperative cardiovascular evaluation and management of patients undergoing non-cardiac surgery recognise higher complications and mortality in PH [27]. The presence of PH is independently associated with perioperative major adverse cardiovascular and cerebral events during non-cardiac surgery [28]. Most of the complications occurs during and within $48 \mathrm{~h}$ after surgery [29]. Acute respiratory failure and RV failure are the major contributors to mortality [30].

Perioperative complications are more frequent in emergency surgery than elective procedures [29, 31]. Data from a prospective multicentre survey demonstrated that emergency noncardiac surgery in PAH patients is a high-risk procedure with a 2.4 times higher likelihood of worse outcome [32]. Furthermore, patients with $\mathrm{PH}$ are more likely to develop postoperative heart failure, pulmonary embolism, haemodynamic instability, sepsis, respiratory failure, renal insufficiency, hepatic dysfunction, myocardial infarction, delayed extubation, longer intensive care unit (ICU) stay and higher 30-day readmission rates [28, 33, 34].

Most of those studies reporting morbidity and mortality in PH patients are retrospective, without matched controls, and were conducted at tertiary referral centres [35]. Perioperative mortality in patients with precapillary $\mathrm{PH}$ is variable, reported as high as $18 \%$ (table 1), with a higher risk in $\mathrm{PAH}$ patients than $\mathrm{PH}$ from other groups. KAw et al. [33] reported a morbidity rate of 41\% in PAH, 16\% in CTEPH and 24\% in group $5 \mathrm{PH}$. In this study, only one patient died (1\%). The low mortality may be explained by the inclusion of mostly postcapillary $\mathrm{PH}(40 \%)$ or Cpc-PH (48\%), which are at a lower risk of complications as compared to PAH patients. Even though mortality remains high with surgery in PAH patients, it has decreased over the years, from $18 \%$ in the first study to $3 \%$ in the 2010 s. Studies assessing mortality in PH during non-cardiac surgery are illustrated in table 1.

\section{Management of perioperative RV dilatation/dysfunction}

Precapillary PH is a major contributor of RV failure perioperatively and postoperative survival is markedly reduced once RV failure sets in. The primary objective in the management is prevention of RV 
TABLE 1 Studies showing the prevalence of perioperative complications after non-cardiac surgery in pulmonary hypertension (PH) patients

\begin{tabular}{|c|c|c|c|c|c|c|c|c|}
\hline Authors, year [ref.] & Study type & $\mathrm{N}$ & $\begin{array}{c}\mathrm{PH} \\
\text { diagnosis }\end{array}$ & $\begin{array}{c}\text { Aetiology of } \\
\text { PH }\end{array}$ & GA & $\begin{array}{l}\text { Major } \\
\text { surgery }\end{array}$ & Mortality & Morbidity \\
\hline $\begin{array}{l}\text { RamaKRISHNA et al. } \\
2005 \text { [34] }\end{array}$ & Retrospective no control & 145 & TTE or RHC & $\begin{array}{l}\text { Group } 145 \% \\
\text { Group } 319 \% \\
\text { Group } 48 \%\end{array}$ & $100 \%$ & $79 \%$ & $7 \%$ & $42 \%$ \\
\hline Minal et al. 2006 [36] & Retrospective no control & $28^{\#}$ & RHC & Group 1 100\% & $79 \%$ & $86 \%$ & $18 \%$ & $19 \%$ \\
\hline LAl et al. 2007 [37] & Retrospective no control & 62 & TTE & $\begin{array}{l}\text { Group } 118 \% \\
\text { Group } 221 \% \\
\text { Group } 321 \%\end{array}$ & $58 \%$ & $65 \%$ & $9.7 \%$ & $24 \%$ \\
\hline PRICE et al. 2010 [29] & Retrospective no control & 28 & $\mathrm{RHC}$ & $\begin{array}{l}\text { Group } 172 \% \\
\text { Group } 428 \%\end{array}$ & $50 \%$ & $57 \%$ & $7 \%$ & $29 \%$ \\
\hline $\begin{array}{l}\text { Memtsoudis et al. } \\
2010 \text { [38] }\end{array}$ & $\begin{array}{l}\text { Retrospective } 1: 3 \text { matching } \\
\text { with no-PH }\end{array}$ & 3543 & $\begin{array}{c}\text { Not } \\
\text { specified }\end{array}$ & NA & NA & $\begin{array}{l}100 \%(\mathrm{THR} / \\
\text { TKR) }\end{array}$ & $\begin{array}{l}2.4 \% \text { (versus } 0.9 \% \\
\text { in no- } \mathrm{PH} \text { ) }\end{array}$ & NA \\
\hline Kaw et al. 2010 [33] & Retrospective controlled & 96 & $\mathrm{RHC}$ & $\begin{array}{l}\text { Group } 112 \% \\
\text { Group } 240 \% \\
\text { Group } 548 \%\end{array}$ & $100 \%$ & $48 \%$ & $1 \%$ & $28 \%$ \\
\hline $\begin{array}{l}\text { MeYer et al. } 2013 \\
\text { [32] }\end{array}$ & Prospective no control & 114 & RHC & Group $1100 \%$ & $82 \%$ & $69 \%$ & $3.5 \%$ & $6.1 \%$ \\
\hline $\begin{array}{l}\text { SEYFARTH et al. } 2015 \\
\text { [39] }\end{array}$ & Retrospective no control & 31 & $\mathrm{RHC}$ & $\begin{array}{l}\text { Group } 174 \% \\
\text { Group } 310 \% \\
\text { Group } 416 \%\end{array}$ & $77 \%$ & $100 \%$ & $3 \%$ & $25 \%$ \\
\hline $\begin{array}{l}\text { SMILOWITZ et al. } 2019 \\
\quad[40]\end{array}$ & Retrospective controlled & 3500 & Variable & Group 1 100\% & NA & All types & $8.3 \%$ & $12.9 \%$ \\
\hline $\begin{array}{l}\text { DeLsou et al. } 2019 \\
\quad \text { [41] }\end{array}$ & Retrospective no control & 196 & RHC & $\begin{array}{l}\text { Group } 174 \% \\
\text { Group } 314 \% \\
\text { Group } 413 \%\end{array}$ & $100 \%$ & $45 \%$ & $3 \%$ & $27 \%$ \\
\hline
\end{tabular}

GA: general anaesthesia; NA: not available; RHC: right heart catheterisation; TTE: transthoracic echocardiography; THR: total hip replacement; TKR: total knee replacement. ": N=21 patients underwent 28 procedures. ": 149 (4.3\%) patients had RHC, others were reported PAH.

dysfunction. Haemodynamically, mPAP is determined by PAWP, PVR and CO as mPAP=PAWP+(CO $\times$ PVR). Any disturbance in one of these variables can impact mPAP and lead to RV dysfunction. During the perioperative period, several factors interact in a complex way to affect the above elements, causing RV dilatation/dysfunction (figure 1). PH patients with hypertrophied RV have a limited adaptive ability to respond to additional disturbance in RV myocardial perfusion and afterload during surgery. Even a slight increase in afterload results in a marked reduction in RV stroke volume [20]. The RV dysfunction, with consequent low $\mathrm{CO}$ and increased RV filling pressure, leads to multi-organ dysfunction due to decreased perfusion pressure. Furthermore, RV ischaemia from low CO and/or hypotension can worsen RV function perioperatively [24].

General anaesthesia induction may be associated with a sudden drop in cardiac preload induced by vasoplegia. When hypertrophied, the RV becomes much more preload-dependent, and a decrease in preload can cause a fall in CO. General anaesthesia can also contribute to systemic hypotension that could affect coronary perfusion and induce RV ischaemia.

Positive pressure ventilation increases intrathoracic pressure, which in turn raises mPAP and reduces the venous return reducing preload of the RV. In addition, it induces alveolar distension with an increase in the transpulmonary pressure responsible for elevating PVR and a decrease in LV preload. Decreased LV preload may also be aggravated by RV overdistension secondary to elevated mPAP [42].

Preserving optimum RV preload is paramount to preserve RV function. The RV has a less steep FrankStarling curve than the LV; hence, there is a smaller change in RV contractility over a wider range of RV filling [43]. Additionally, RV dilation from an excessive volume load increases RV free wall tension and impairs RV perfusion. Inadequate vascular filling can be deleterious in these patients. A sudden rise in RV preload, exceeding the adaptive capacities of the RV, precipitates right heart failure. Consequently, it induces venous congestion and dysfunction of upstream organs (kidney and liver in particular). Hypo- or hypervolemia can also trigger supraventricular arrythmias and contribute to further decrease stroke volume. 

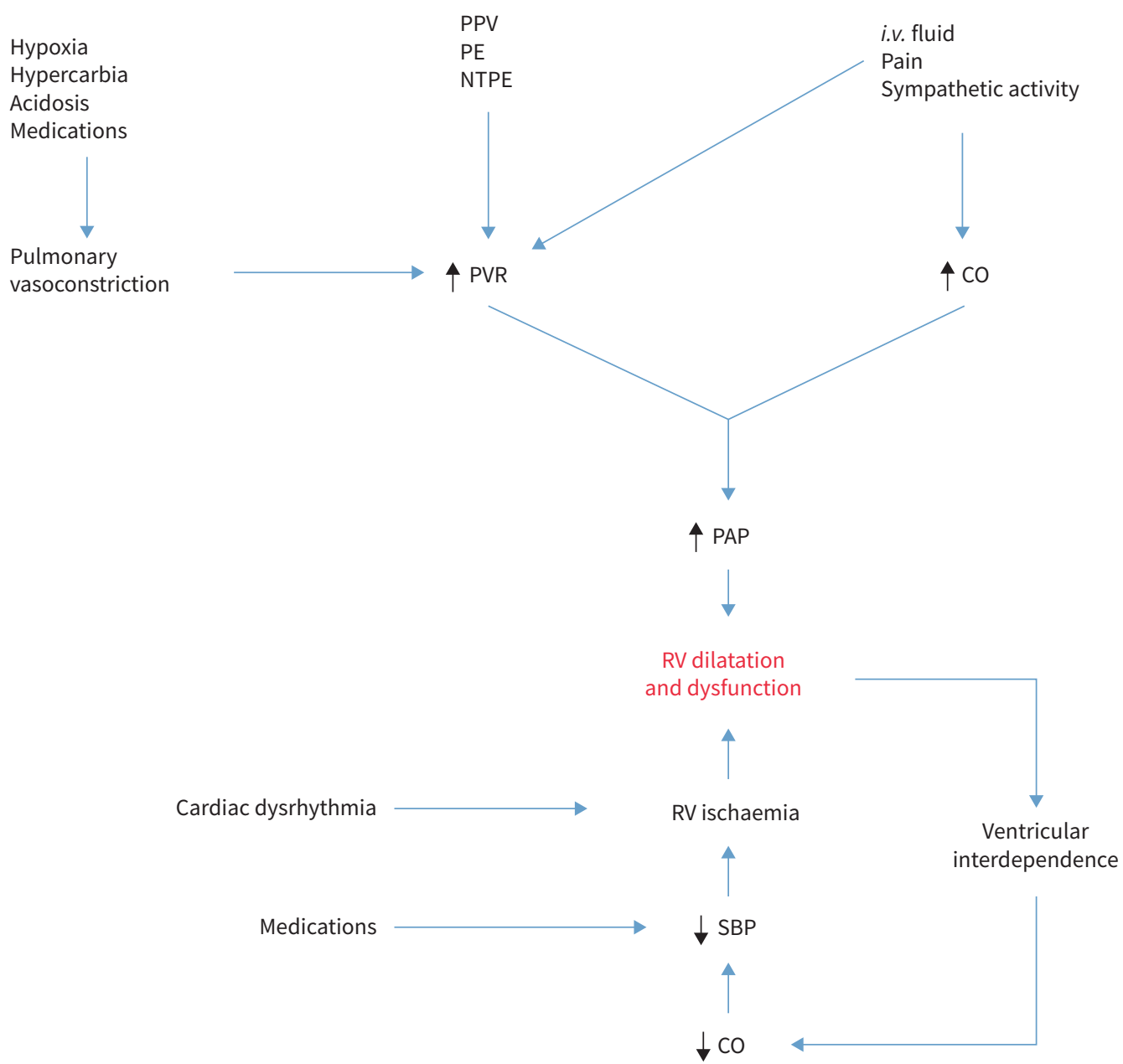

(pronounced in RV dilatation dysfunction)

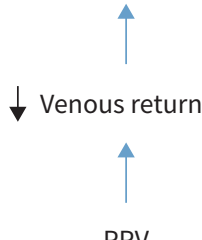

PPV

FIGURE 1 Factors worsening pulmonary artery pressure and consequent right ventricular dilatation/ dysfunction in the perioperative period. CO: cardiac output; NTPE: non-thrombotic pulmonary embolism; PAP: pulmonary artery pressure; PE: pulmonary embolism; PPV: positive pressure ventilation; PVR: pulmonary vascular resistance; RV: right ventricle; SBP: systolic blood pressure.

Hypoxia, hypercapnia and hypothermia can all cause pulmonary vasoconstriction and increase PVR, which can lead to right heart failure [42]. They must therefore be prevented and avoided.

In acute RV failure, maintaining mean arterial pressure (MAP) is key to supporting RV performance by preserving coronary perfusion [44]. Norepinephrine is the first-line treatment in most centres. Vasopressin, a $V_{1}$ receptor stimulator on vascular smooth muscle, could also be interesting because it is a systemic vasoconstrictor while not affecting PVR [45]. Notwithstanding, vasopressin's clinical use in PH has not been adequately studied yet.

Inotropes could be used in cases of RV failure with low CO. Few studies have evaluated their use in the setting of RV failure in precapillary PH patients. Dobutamine ( $\beta 1$-adrenergic receptor agonist) and milrinone (selective phosphodiesterase-3 inhibitor) improve RV contractility and help to recruit further 
pulmonary vasculature, therefore reducing PVR [46]. At a high dose, dobutamine can decrease systemic arterial pressure without improving CO [47], it should be started at low dose $\left(2.5 \mu \mathrm{g} \cdot \mathrm{kg}^{-1} \cdot \mathrm{min}^{-1}\right)$ and uptitrated to $10 \mu \mathrm{g} \cdot \mathrm{kg}^{-1} \cdot \mathrm{min}^{-1}$. A comparative observational study showed a greater occurrence of hypotension with milrinone than with dobutamine [48]. In contrast, milrinone has fewer chronotropic effects compared to dobutamine, consequently lowering the incidence of tachyarrhythmias [43]. Milrinone also increases RV/PA coupling, improves RV contractility and decreases PVR in PH patients [49]. Milrinone is commonly available for intravenous (i.v.) administration, but also in inhaled form [50]. Inhaled milrinone decreases mPAP, PVR, transpulmonary gradient (TPG) and PVR/ systemic vascular resistance ratio during surgery, as well [51]. Nebulised milrinone has demonstrated synergistic action along with inhaled prostacyclin in patients with severe postcapillary PH [52]. Levosimendan, a calcium sensitiser, can lower mPAP and RV afterload in RV failure [53]. A pilot study utilising levosimendan showed its efficacy in improving pulmonary haemodynamics, although the study was conducted predominantly in patients with group $2 \mathrm{PH}$ [54]. However, its usefulness needs to be validated in larger clinical trials.

Inhaled NO (pulsed delivery or continuously up to $20 \mathrm{ppm}$ ) or iloprost (nebulisation, 5-10 $\mu$ g every 2-4 h) could be useful to quickly reduce RV afterload by acute pulmonary vasodilation intraoperatively [55]. The advantage of inhalation therapy over i.v. is the lower incidence of systemic hypotension. Inhaled therapies also cause preferential pulmonary vasodilation in well-ventilated lung zones, ameliorating $V^{\prime} / Q^{\prime}$ mismatch [43]. There are conflicting data on phosphodiesterase-5 inhibitor sildenafil to treat PH and RV failure post-surgery. Sildenafil significantly lowers systolic PAP intraoperatively without impacting any other haemodynamics [56]. However, a large multicentric randomised trial failed to show any beneficial outcome effect noted in previous small trials [56, 57].

Venoarterial extracorporeal membrane oxygenation (VA ECMO) allows bypassing the pulmonary vascular bed with an immediate decrease in RV preload and afterload and restoration of a good systemic arterial pressure and organ perfusion. However, this technique can lead to serious complications such as major bleeding, lower-limb ischaemia, thromboembolic manifestations, neurological sequelae or infection [43]. VE ECMO should be proposed in cases of RV failure refractory to optimal medical treatment and with an anticipation of rapid recovery or as a bridge to lung transplantation [20]. It has been used successfully in awake, spontaneously breathing treatment-naïve patients during initiation of a pulmonary vasodilator in severe RV failure.

Clinically, RV impairment translates into a significantly higher occurrence of cardiogenic shock, in-hospital and short-term mortality. Yet, maintaining RV performance is challenging in the perioperative period. The management of RV function focusses on optimising RV preload, preventing RV ischaemia, improving RV contractility and minimising RV afterload (Supplementary table ST4).

Preoperative evaluation of $\mathrm{PH}$ patients

\section{Preoperative risk stratification}

It is imperative to perform a preoperative risk assessment and implement strategies to prevent perioperative complications in $\mathrm{PH}$ patients. A limited number of small retrospective and prospective studies have identified potential risk factors in this cohort (table 2). Foremost risk elements are WHO functional class III or IV [41], and 6MWD $<300 \mathrm{~m}[30,60]$ and N-terminal pro-brain natriuretic peptide (NT-proBNP) $>300 \mathrm{pg} \cdot \mathrm{mL}^{-1}[41]$.

The presence of RV strain and right axis deviation on electrocardiogram [30] and RV hypertrophy and RV index of myocardial performance $\geqslant 0.75$ on echocardiography are associated with perioperative RV dysfunction [34, 59,60]. Additional reported adverse haemodynamic risk factors were mPAP $>50 \mathrm{mmHg}$, PVR 8.6 WU [61].

\section{Preoperative management}

When surgery is considered in PH patients, it is essential to consider the type of surgery, evaluate the WHO functional class, severity of PH and RV function. Elevated jugular venous pressure, right third heart sound, hepatomegaly, ascites, and pedal oedema suggest presence of RV failure [30].

Preoperative laboratory tests should include a complete blood count, metabolic panel and NT-proBNP. Congestive hepatopathy and cardio-renal syndrome due to right heart failure causes elevated liver transaminases and creatinine, respectively. Transthoracic echocardiography is an accessible exam that allows estimating the RV systolic pressure (RVSP), right-sided chamber size and function. The presence of pericardial effusion, RV hypertrophy, RV myocardial performance index (RVMPI) $\geqslant 0.75$ and 


\section{TABLE 2 Risk factors for perioperative morbidity and mortality in pulmonary hypertension patients}

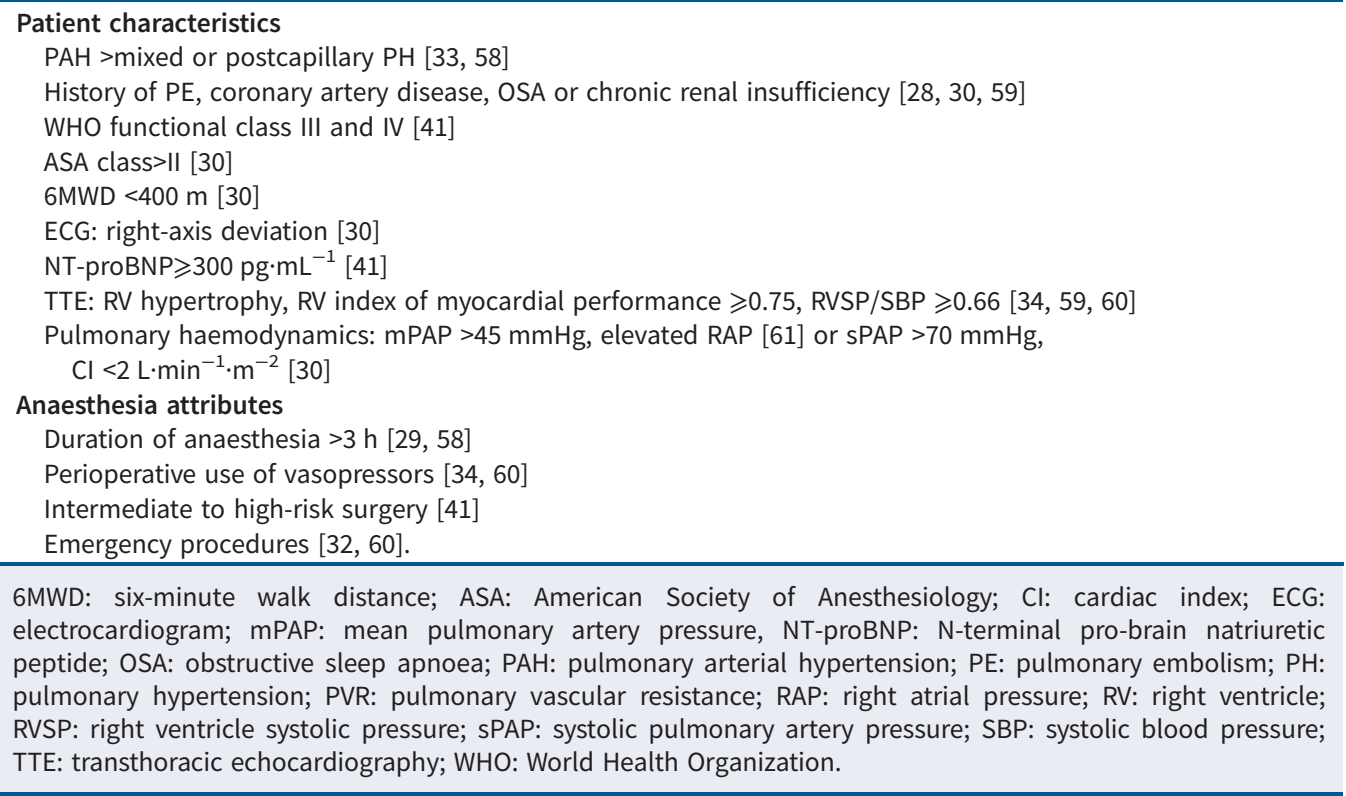

RVSP/SBP $\geqslant 0.66$ were also associated with early perioperative mortality in these patients [46]. However, echocardiography can underestimate RVSP and, thus, other markers of RV dysfunction such as tricuspid plane annular excursion, RV fractional shortening, RVMPI and RV global longitudinal strain should be estimated [62]. A flattened septum or paradoxical septal motion indicates RV pressure and volume overload [62].

RHC is not routinely required but may be considered prior to surgery in selected patients with moderate to severe PH. It allows the accurate assessment of RAP, systolic PAP and mPAP, higher values of which are associated with poor perioperative outcome $[30,60]$. RHC should be performed if echocardiography shows an estimated RVSP>50 mmHg and/or RV enlargement.

PH medications should not be withdrawn abruptly since rebound PH and adverse outcomes are reported [63]. Escalation of pulmonary vasodilators could be useful in selected patients with risk factors of perioperative complications (table 2). A trial of oral sildenafil, inhaled NO and inhaled prostacyclin iloprost have been proposed to manage perioperative $\mathrm{PH}[64,65]$. They have a rapid onset but relatively short duration of action. Inhaled NO and inhaled iloprost during the perioperative period decrease PVR, improve RV function and increase CO [64]. Inhaled iloprost has a longer half-life (20-30 min), therefore it can be administered intermittently. Inhaled iloprost was superior to inhaled NO in reducing PAP, PVR and improving CO during and after surgery in PH in direct comparison [46]. Nebulised treprostinil has not yet been studied in the perioperative period. The utility of other pulmonary vasodilators has not been evaluated in the perioperative period, possibly due to their slower onset of action and requirement for gradual uptitration of dosage. WANG et al. [66] reported the safety and efficacy of rapid uptitration of i.v. treprostinil in pregnancy with severe $\mathrm{PH}$; those patients subsequently underwent caesarean section.

BPA procedures have been described with promising results in preoperative management of selected patients with CTEPH undergoing noncardiac surgery and can be proposed in non-urgent surgery [67, 68]. Multiple sessions of BPA were employed in CTEPH patients to reduce mPAP below $30 \mathrm{mmHg}$ prior to total hysterectomy and knee arthroplasty, which resulted in a successful outcome [67, 68].

It is critical that a multidisciplinary team coordinates the care of these patients, including PH specialists, surgeons, cardiologists, anaesthesiologists and intensivists [30]. The appropriate use of pulmonary vasodilators to stabilise haemodynamics and adequate surgical planning are essential in the preoperative period [69]. We propose an algorithm for preoperative approach for patients with $\mathrm{PH}$ in supplementary figure S1. 
Intraoperative management of $\mathrm{PH}$

The goal of intraoperative management is directed at preventing RV failure by optimising RV preload, decreasing RV afterload and improving RV contractility. A goal-directed approach based upon understanding of pathophysiology to promptly address those factors is imperative.

\section{General measures}

Supplemental oxygen should be used to preserve $S_{\mathrm{pO}_{2}} \geqslant 92 \%$. All precautions should be taken to avoid any amount of air embolism. PH patients are more sensitive to the introduction of even small amounts of air into the pulmonary circulation. Hypothermia must be prevented, as it causes pulmonary vasoconstriction. Other factors such as anxiety, pain, blood loss or Trendelenburg positioning can affect pulmonary haemodynamics by releasing endogenous pulmonary vasoconstrictors. Some authors recommend maintaining intraoperative PAP within 15\% range of baseline [70], but this target is yet to be evaluated properly in well-designed clinical studies. The intraoperative haemodynamic goals in these patients are described in figure 2.

\section{Intraoperative monitoring}

The first haemodynamic goal is to prevent hypotension in order to maintain a sufficient coronary perfusion. Invasive arterial blood pressure must be monitored before induction. An uncalibrated pulse contour analysis system can be used to monitor stroke volume and CO [71]. Monitoring central venous

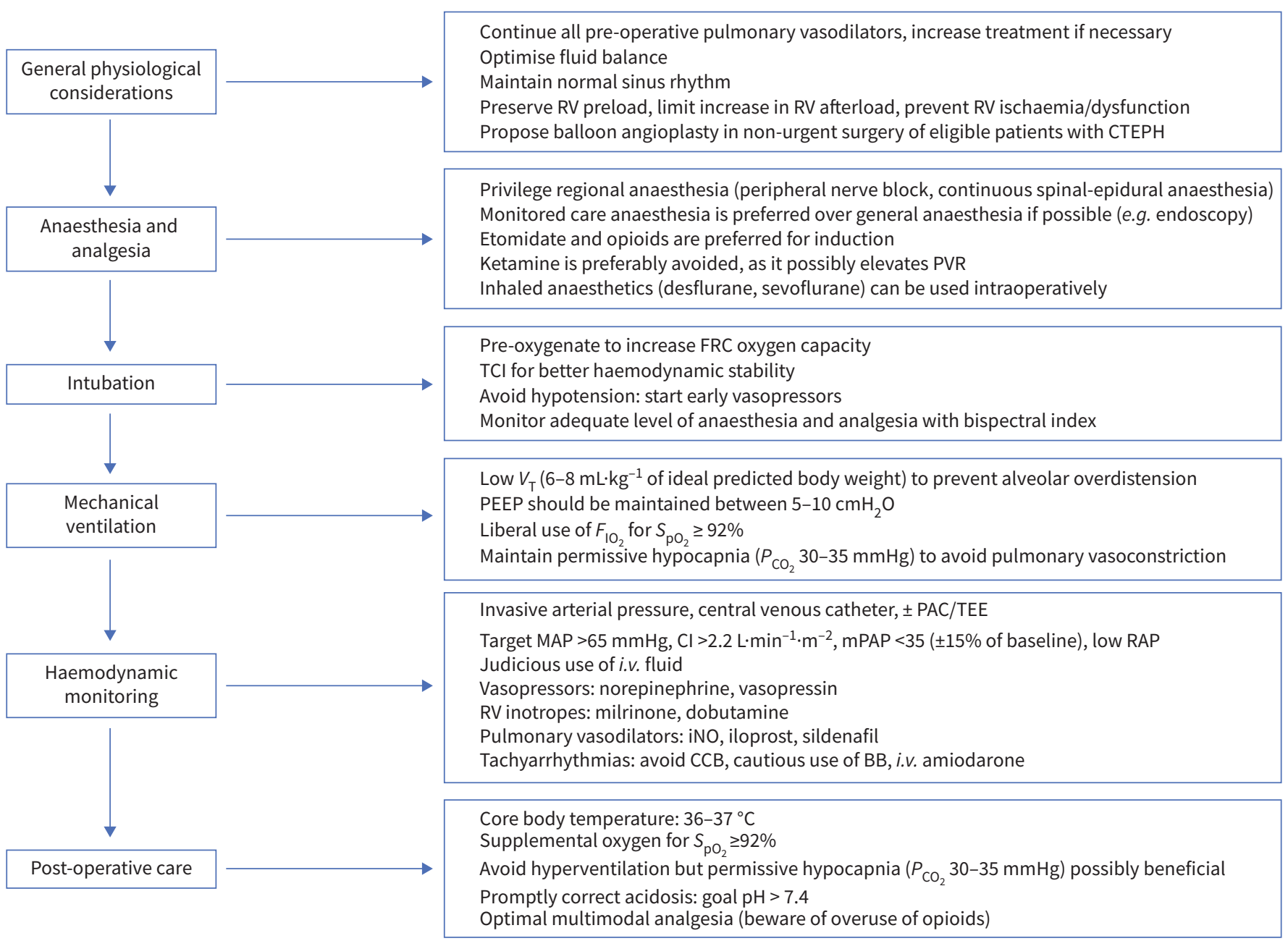

FIGURE 2 Suggested intraoperative monitoring and interventions in pulmonary hypertension patients [30, 49]. BB: beta blocker; CCB: calcium channel blocker; $\mathrm{Cl}$ : cardiac index; $\mathrm{CTEPH}$ : chronic thromboembolic pulmonary disease; $F_{\mathrm{IO}_{2}}$ : fractional inspired oxygen; FRC: functional residual capacity; iNO: inhaled nitric oxide; MAP: mean arterial pressure; mPAP: mean pulmonary artery pressure; PAC: pulmonary artery catheter; $P_{\mathrm{CO}_{2}}$ : carbon dioxide tension; PVR: pulmonary vascular resistance; PEEP: positive end expiratory pressure; RAP: right atrial pressure; RV: right ventricle; $\mathrm{S}_{\mathrm{PO}_{2}}$ : oxygen saturation; $\mathrm{TCl}$ : target controlled infusion; TEE: transoesophageal echocardiogram; $V_{\mathrm{T}}$ : tidal volume. 
pressure (CVP) is useful for judicious administration of fluids and to detect diastolic RV failure. Although a static value of CVP is not appropriate to predict the response to fluid administration [72], dynamic changes during surgery could be informative. Decreases in MAP and CVP would indicate a potential decrease in preload, while a decrease in MAP with an increase in CVP would be in favour of RV failure.

A pulmonary artery catheter (PAC) can be an alternative. Its advantages are the ability to monitor acute changes in PAP, TPG, mixed venous oxygenation, RV function and CO in response to any intervention. Pre-induction PAC placement can help in intracardiac monitoring in cases of haemodynamic instability and titration of induction/vasoactive/inotropic agents where transoesophageal echocardiography (TEE) is not an option [42]. However, the risks versus benefits of this approach must be considered [73]. PAC placement is not required in patients with mild to moderate $\mathrm{PH}$ undergoing low risk surgical procedures. TEE can be a potential alternative to PAC for intraoperative haemodynamic assessment. TEE can be used to monitor systolic PAP, RV function, LV function, intraventricular thrombus and to guide fluid management. Importantly, TEE may not detect early acute RV dysfunction because RV end diastolic volume must change several times prior to a corresponding increase in RV end diastolic pressure [74]. Nonetheless, studies have shown that TEE positively impacts management in noncardiac surgeries during the intraoperative period [75]. Intraoperative TEE has aided in the detection of ventricular fibrillation, cardiac dysfunction, myocardial infarction and cardiac shunt. However, the quality of those studies had critical deficiencies including selection bias, nonrandomisation and an underpower sample size [75].

\section{Airway management and ventilation}

PH patients are particularly vulnerable during the induction phase of general anaesthesia. Hypoxaemia, hypercapnia and acidosis increase pulmonary vasoconstriction. The goal of ventilation is to maintain $\mathrm{pH} \geqslant 7.4, S_{\mathrm{pO}_{2}} \geqslant 92 \%$ and $P_{\mathrm{aCO}_{2}} 30-35 \mathrm{mmHg}$. Appropriate induction of anaesthesia is pivotal in management of these patients. Pre-oxygenation to fill the lung to functional residual capacity (FRC) and an adequate level of analgesia prior to laryngoscopy are important. The depth of anaesthesia can be monitored with a bispectral index monitor. There is potential for considerable sympathetic stimulation during laryngoscopy. The addition of i.v. lidocaine $1-2 \mathrm{mg} \cdot \mathrm{kg}^{-1}$ with or without fentanyl $1-2 \mu \mathrm{g} \cdot \mathrm{kg}^{-1}$ helps attenuate the cardiovascular response to laryngoscopy [76]. Likewise, awake fibreoptic intubation with adequate topicalisation can be performed to avoid poor ventilation and oxygenation, associated with deeper sedation. The tidal volume $\left(V_{\mathrm{T}}\right)$ should be targeted at normal FRC and positive end expiratory pressure $<10 \mathrm{mmHg}$ [60]. The relationship of $V_{\mathrm{T}}$ and PVR is U-shaped with the lowest PVR at FRC.

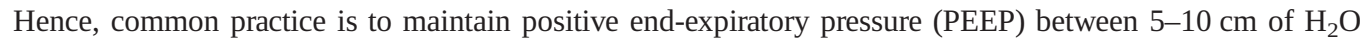
and increase oxygenation, rather than PEEP, to mitigate hypoxaemia and moderate minute ventilation.

\section{Anaesthesia in $\mathrm{PH}$}

Currently, there are no evidence-based guidelines regarding technique or choice of anaesthesia. In a meta-analysis totalling 73 PAH obstetric deliveries, general anaesthesia was associated with a fourfold increase in mortality compared to regional anaesthesia [77]. Moreover, several studies found a trend of increased complication with general anaesthesia during surgery [57] and gastro-intestinal endoscopy [78]. Monitored anaesthesia care with local anaesthesia is convenient and preferable for these patients [79]. Regional anaesthesia reduces the complications related to intubation, haemodynamic instability and increased PAP from mechanical ventilation [80]. Epidural anaesthesia has the additional benefit of providing postoperative pain control and causing less hypotension compared to spinal anaesthesia. Continuous spinal anaesthesia with low dose anesthetics or combined spinal-epidural anaesthesia have been proposed and seem attractive approaches in delivery of pregnant PH patients [81] or in hip fracture surgery [82]. However, no study has compared general to regional anaesthesia in these patients.

The ideal anaesthetic agent should attenuate hypoxic pulmonary vasoconstriction, minimise intraoperative elevation in PVR, maintain RV function and sustain adequate anaesthesia and analgesia. There are scarce data comparing the haemodynamic effects of different anaesthetic agents in patients with PH. Most currently available i.v. anaesthetics can negatively impact RV contractility or adversely affect the autonomic nervous system [60, 83]. Some authors recommend etomidate as an i.v. induction agent of choice in the presence of RV dysfunction, given its negligible effect on the pulmonary vascular bed and RV contractility [83]. Fentanyl and sufentanil also have a minimal effect on pulmonary haemodynamics and are neutral to RV contractility, while remifentanil can affect pulmonary vasculature secondary to histamine release [84]. The rapid onset and offset of action of remifentanil is useful as an adjunct anaesthetic agent or for rapid onset hyperalgesia [85]. Ketamine is usually not recommended in adult patients with PH due to reported increase in mPAP and PVR in healthy patients [86, 87]. However, more recent data on children with PH reported no change in PVR and the change in mPAP was not clinically relevant, appeared safe [88-91]. The potential deleterious effects of ketamine on PVR must be balanced 
against the potential benefits of combined analgesia and hypnosis, as well as absence of significant myocardial depression and vasodilation. Ketamine avoids the likely problem of adrenal insufficiency implicated with etomidate [92] and it does not decrease the endogenous sympathetic tone, unlike large doses of opioids. Propofol might decrease RV contractility by direct negative inotropic action and can cause profound hypotension [55]. The target-controlled infusion method is an automated i.v. drug administration technique in which specifically designed software adjusts the rate of drug delivery to achieve an anticipated, user-adjustable target concentration of the drug (usually propofol and remifentanil) and it allows a titration with better haemodynamic stability [93, 94]. Still, it is prudent to consider concomitant administration of catecholamines like norepinephrine or dobutamine to counteract the myocardial depression and haemodynamic instability [95] associated with general anaesthesia.

Volatile agents are commonly used for maintenance of anaesthesia. Isoflurane and desflurane have a dose-dependent effect in decreasing RV contractility and increasing RV afterload with no change in PVR; hence, they significantly impair RV/PA coupling [96]. Sevoflurane causes a significant depression of RV function without any modification of PVR [97]. In a rat model of RV hypertrophy, desflurane was associated with fewer RV haemodynamic effects compared to sevoflurane and isoflurane [98]. These data need to be confirmed in humans. Nitrous oxide increases PVR and RV afterload and should be avoided [99]. All inhaled anaesthetics depress RV in a dose-dependent manner. Table 3 summarises the effects of anaesthetics on pulmonary vasculature and RV function.

\section{Special surgical populations}

Certain surgical procedures carry greater risk for patients with PH. Therefore, recognition and mitigation of potential complications are paramount.

\section{Orthopaedic surgery}

A high perioperative risk occurs in patients undergoing hip and knee replacement or repair of hip fractures [105]. Those surgeries are associated with an increased risk of bleeding and thrombotic/non-thrombotic pulmonary embolism, leading to a subsequent acute increase in PVR, RV afterload and hypotension. Some authors recommend pre-emptive use of inotropes in the presence of RV dysfunction to attenuate the effects of emboli associated with long bone rodding [60]. In addition, cementless joint replacement is favoured to

TABLE 3 Effects of anaesthetic agents, vasopressors and inotropes on pulmonary vasculature and right ventricle function $[42,47,96,97,100,101]$

\begin{tabular}{|c|c|c|c|}
\hline Agents & MPAP & PVR & RV contractility \\
\hline \multicolumn{4}{|l|}{ Anaesthetic agents } \\
\hline Isoflurane & $\downarrow$ & $\leftrightarrow$ & $\downarrow \downarrow$ \\
\hline Desflurane & $\downarrow$ & $\leftrightarrow$ & $\downarrow \downarrow$ \\
\hline Sevoflurane & $\downarrow$ & $\leftrightarrow$ & $\downarrow \downarrow$ \\
\hline Nitrous oxide & $\uparrow \uparrow$ & $\uparrow \uparrow$ & $\downarrow$ \\
\hline Thiopental sodium & $\leftrightarrow$ & $\leftrightarrow$ & $\downarrow$ \\
\hline Etomidate & $\leftrightarrow$ & $\leftrightarrow$ & $\leftrightarrow$ \\
\hline Ketamine & $\uparrow$ & $\leftrightarrow / \uparrow$ & $\downarrow$ \\
\hline Propofol & $\downarrow$ & $\downarrow$ & $\downarrow \downarrow$ \\
\hline Fentanyl/sufentanil & $\leftrightarrow$ & $\leftrightarrow$ & $\leftrightarrow$ \\
\hline Remifentanil & $\leftrightarrow$ & $\leftrightarrow$ & $\leftrightarrow$ \\
\hline \multicolumn{4}{|l|}{ Vasopressors } \\
\hline Norepinephrine & $\uparrow$ & $\uparrow$ & $\uparrow$ \\
\hline Epinephrine & $\uparrow$ & $\uparrow$ & $\uparrow$ \\
\hline Phenylephrine & $\uparrow$ & $\uparrow$ & $\downarrow \downarrow$ \\
\hline Vasopressin & $\downarrow$ & $\downarrow$ & $\leftrightarrow$ \\
\hline \multicolumn{4}{|l|}{ Inotropes } \\
\hline Dobutamine & $\leftrightarrow$ & $\uparrow, \leftrightarrow, \downarrow^{\#}$ & $\uparrow \uparrow$ \\
\hline Milrinone & $\leftrightarrow$ & $\downarrow$ & $\uparrow \uparrow$ \\
\hline Levosimendan & $\downarrow$ & $\downarrow$ & $\uparrow$ \\
\hline
\end{tabular}


minimise risk of emboli during surgery [106]. Epidural analgesia or lower ipsilateral extremity nerve block is preferred to avoid the haemodynamic instability associated with general anaesthesia. Continuous spinal anaesthesia has also been proposed with good outcomes [82].

\section{Laparoscopic surgery}

Although "minimally invasive", laparoscopic surgery poses a significant risk in patients with $\mathrm{PH}$, particularly in extremes of Trendelenburg and reverse Trendelenburg positions [107]. Pneumoperitoneum from $\mathrm{CO}_{2}$ insufflation increases intra-abdominal pressure and airway pressure, decreases venous return and affects lung compliance [107]. Consequently, patients develop $V^{\prime} / Q^{\prime}$ mismatch and increased intrapulmonary shunting leading to hypoxia, a rise in PAP and RV afterload. Importantly, these haemodynamic changes are not immediately reversed after resolution of the pneumoperitoneum. Persistent $\mathrm{CO}_{2}$ absorption can cause hypercarbia and respiratory acidosis, leading to late pulmonary vasoconstriction and increased RV afterload. Nevertheless, all laparoscopic procedures are not associated with this deleterious haemodynamic effect. Robot-assisted pelvic surgery, such as prostatectomy or hysterectomy, are less impactful on haemodynamics than upper abdominal surgery, e.g., cholecystectomy, because of the need for prolonged reverse Trendelenburg positioning in the latter.

\section{Gastrointestinal endoscopy}

In a retrospective study of 37 gastrointestinal endoscopy including oesophagogastroduodenoscopy, colonoscopy and endoscopic retrograde cholangiopancreatography, major complications occurred in $14 \%$ of the cases, although $84 \%$ of the procedures were performed with sedation only [78]. It was much higher than the rate reported in American Society of Anesthesia patients having gastrointestinal procedures (1.8\%) [108]. Emergency and endoscopic retrograde cholangiopancreatography procedures were associated with significant perioperative complications, as well.

\section{Postoperative care of patients with $\mathrm{PH}$}

Postoperative patients with severe $\mathrm{PH}$ are often managed in the ICU for several days to address factors associated with a sudden increase in RV afterload and acute RV failure [109]. Most of the perioperative complications occur in the first $72 \mathrm{~h}$ of postoperative period [57]. Evidence suggests that $\mathrm{PH}$ itself aggravates a marked sympathetic activity [20], which leads to elevation in PVR and RV failure [110]. Postoperative pain and anxiety control is important to prevent sympathetic overactivation, without overuse of sedatives and opioid analgesics. Paradoxically, these agents can cause respiratory depression and subsequent alveolar hypoventilation with hypoxia, hypercarbia and acidosis, increasing PVR [61]. Postoperatively, non-opioid analgesics are often used for this reason.

Adequate oxygenation in the perioperative period is imperative. Non-invasive ventilation or high-flow oxygen have been proposed after major abdominal surgery [111] in order to prevent respiratory failure. However, its utility in PH patients with non-obstructive sleep apnoea remains unknown [112]. Notably, the American Society of Anesthesiology guideline for perioperative management cautions against excessive use of supplemental oxygen as it may accentuate hypoventilation, prolong duration of apnoeic episodes and hinder the detection of atelectasis [113].

No precise haemoglobin level has been studied to improve patient outcome, especially in patients with precapillary PH. Nevertheless, anaemia with haemoglobin $<10 \mathrm{~g} \cdot \mathrm{dL}^{-1}$ should be promptly corrected since it affects oxygen transport, increases metabolic demands and exacerbates RV workload and ischaemia [114]. Cardiac arrhythmias should be treated cautiously; calcium channel blockers and betablockers may worsen RV function, given their negative inotropic and chronotropic effects. However, a recent study has noted the safety and tolerability of beta blockers in selected patients [115].

Life-threatening rebound $\mathrm{PH}$ can occur when patients are weaned too rapidly from inhaled NO. Use of sildenafil for transition may be useful to negate this rebound $\mathrm{PH}$ [56]. In a small observational series, iloprost and i.v. epoprostanol were successfully used to preserve pulmonary haemodynamics and RV function after weaning from cardiopulmonary bypass [55]. Restoration of adequate perfusion pressure and avoidance of hypotension in the postoperative period is important to offset RV ischaemia and dysfunction.

In conclusion, $\mathrm{PH}$ is a chronic progressive disease leading to RV dysfunction and death. While the burgeoning array of pulmonary vasodilators have improved outcomes, $\mathrm{PH}$ remains a great challenge for anaesthesiologists. The presence of $\mathrm{PH}$ is considered an independent risk factor for perioperative morbidity and mortality. Unfortunately, perioperative management of $\mathrm{PH}$ is fraught with difficulty. Currently there are no guidelines for perioperative risk management and the data in the literature is sparse. The crucial objective is prevention of RV dysfunction. Preoperative risk stratification and optimisation of 
haemodynamic parameters are key to achieve a satisfactory outcome. A multidisciplinary team approach to the management of these patients helps achieve this goal.

Provenance: Commissioned article, peer reviewed.

Author contributions: D. Bandyopadhyay contributed in writing, reviewing and editing the manuscript. C. Lai contributed in writing, reviewing and editing the manuscript. J.N. Pulido contributed in writing, reviewing and editing the manuscript. R. Restrepo-Jaramillo contributed in writing, reviewing and editing the manuscript. A.R Tonelli contributed in writing, reviewing and editing the manuscript. M. Humbert contributed in writing, reviewing and editing the final manuscript.

Conflict of interest: D. Bandyopadhyay received fees for a speaker bureau, advisory committee and research grants from Boehringer Ingelheim; and fees for a speaker bureau, advisory committee and research grants from United Therapeutics corporation. C. Lai has nothing to disclose. J.N. Pulido has nothing to disclose. R. Restrepo-Jaramillo received fees for a speaker bureau, advisory committee and research grants from Bayer; fees for a speaker bureau, advisory committee and research grants from Janssen Actelion; and fees for a speaker bureau, advisory committee and research grants from United Therapeutics corporation. A.R. Tonelli has nothing to disclose. M. Humbert reports grants, personal fees and non-financial support from GlaxoSmithKline; personal fees from AstraZeneca, Novartis, Roche, Sanofi, Merck and Teva; and grants and personal fees from Acceleron, Actelion and Bayer, outside the submitted work.

\section{References}

1 Simonneau G, Montani D, Celermajer DS, et al. Haemodynamic definitions and updated clinical classification of pulmonary hypertension. Eur Respir J 2019; 53: 1801913.

2 Humbert M, Sitbon O, Chaouat A, et al. Survival in patients with idiopathic, familial, and anorexigen-associated pulmonary arterial hypertension in the modern management era. Circulation 2010; 122: $156-163$.

3 Benza RL, Miller DP, Gomberg-Maitland M, et al. Predicting survival in pulmonary arterial hypertension: insights from the Registry to Evaluate Early and Long-Term Pulmonary Arterial Hypertension Disease Management (REVEAL). Circulation 2010; 122: 164-172.

4 Hoeper MM, Simon RGJ. The changing landscape of pulmonary arterial hypertension and implications for patient care. Eur Respir Rev 2014; 23: 450-457.

5 Benza RL, Miller DP, Barst RJ, et al. An evaluation of long-term survival from time of diagnosis in pulmonary arterial hypertension from the REVEAL Registry. Chest 2012; 142: 448-456.

6 Strange G, Playford D, Stewart S, et al. Pulmonary hypertension: prevalence and mortality in the Armadale echocardiography cohort. Heart 2012; 98: 1805-1811.

7 Waxman A, Restrepo-Jaramillo R, Thenappan T, et al. Inhaled treprostinil in pulmonary hypertension due to interstitial lung disease. N Engl J Med 2021; 384: 325-334.

8 Kim NH, Delcroix M, Jais X, et al. Chronic thromboembolic pulmonary hypertension. Eur Respir J 2019; 53: 1801915.

9 Jin Q, Zhao ZH, Luo Q, et al. Balloon pulmonary angioplasty for chronic thromboembolic pulmonary hypertension: State of the art. World J Clin Cases 2020; 8: 2679-2702.

10 Simonneau G, D'Armini AM, Ghofrani HA, et al. Riociguat for the treatment of chronic thromboembolic pulmonary hypertension: a long-term extension study (CHEST-2). Eur Respir J 2015; 45: 1293-1302.

11 Galie N, Humbert M, Vachiery JL, et al. 2015 ESC/ERS guidelines for the diagnosis and treatment of pulmonary hypertension: The Joint Task Force for the Diagnosis and Treatment of Pulmonary Hypertension of the European Society of Cardiology (ESC) and the European Respiratory Society (ERS): Endorsed by: Association for European Paediatric and Congenital Cardiology (AEPC), International Society for Heart and Lung Transplantation (ISHLT). Eur Heart J 2016; 37: 67-119.

12 Farber HW, Miller DP, Poms AD, et al. Five-year outcomes of patients enrolled in the REVEAL Registry. Chest 2015; 148: 1043-1054.

13 Benza RL, Gomberg-Maitland M, Elliott CG, et al. Predicting survival in patients with pulmonary arterial hypertension: the REVEAL risk score calculator 2.0 and comparison with ESC/ERS-based risk assessment strategies. Chest 2019; 156: 323-337.

14 Galie N, Barbera JA, Frost AE, et al. Initial use of ambrisentan plus tadalafil in pulmonary arterial hypertension. N Engl J Med 2015; 373: 834-844.

15 Sitbon O, Channick R, Chin KM, et al. Selexipag for the treatment of pulmonary arterial hypertension. $N$ Engl J Med 2015; 373: 2522-2533.

16 Pulido T, Adzerikho I, Channick RN, et al. Macitentan and morbidity and mortality in pulmonary arterial hypertension. N Engl J Med 2013; 369: 809-818. 
Olsson KM, Delcroix M, Ghofrani HA, et al. Anticoagulation and survival in pulmonary arterial hypertension: results from the Comparative, Prospective Registry of Newly Initiated Therapies for Pulmonary Hypertension (COMPERA). Circulation 2014; 129: 57-65.

Preston IR, Roberts KE, Miller DP, et al. Effect of warfarin treatment on survival of patients with pulmonary arterial hypertension (PAH) in the registry to evaluate early and long-term PAH disease management (REVEAL). Circulation 2015; 132: 2403-2411.

Ascha M, Zhou X, Rao Y, et al. Impact on survival of warfarin in patients with pulmonary arterial hypertension receiving subcutaneous treprostinil. Cardiovasc Ther 2017; 35: e12281.

Arrigo M, Huber LC, Winnik S, et al. Right ventricular failure: pathophysiology, diagnosis and treatment. Card Fail Rev 2019; 5: 140-146.

Humbert M, Guignabert C, Bonnet S, et al. Pathology and pathobiology of pulmonary hypertension: state of the art and research perspectives. Eur Respir J 2019; 53: 1801887.

Tonelli AR, Arelli V, Minai OA, et al. Causes and circumstances of death in pulmonary arterial hypertension. Am J Respir Crit Care Med 2013; 188: 365-369.

Hoeper MM, Benza RL, Corris P, et al. Intensive care, right ventricular support and lung transplantation in patients with pulmonary hypertension. Eur Respir J 2019; 53: 1801906.

Piazza G, Goldhaber SZ. Management of submassive pulmonary embolism. Circulation 2010; 122: 1124-1129. Guyton AC, Lindsey AW, Gilluly JJ. The limits of right ventricular compensation following acute increase in pulmonary circulatory resistance. Circ Res 1954; 2: 326-332.

Savale L, Weatherald J, Jaïs X, et al. Acute decompensated pulmonary hypertension. Eur Respir Rev 2017; 26: 170092. evaluation and management of patients undergoing noncardiac surgery: a report of the American College of Cardiology/American Heart Association Task Force on practice guidelines. J Am Coll Cardiol 2014; 64: e77-137.

Smilowitz NR, Armanious A, Bangalore S, et al. Cardiovascular outcomes of patients with pulmonary hypertension undergoing noncardiac surgery. Am J Cardiol 2019; 123: 1532-1537.

Price LC, Montani D, Jais X, et al. Noncardiothoracic nonobstetric surgery in mild-to-moderate pulmonary hypertension. Eur Respir J 2010; 35: 1294-1302.

Aguirre MA, Lynch I, Hardman B. Perioperative management of pulmonary hypertension and right ventricular failure during noncardiac surgery. Adv Anesth 2018; 36: 201-230.

Steppan J, Diaz-Rodriguez N, Barodka VM, et al. Focused review of perioperative care of patients with pulmonary hypertension and proposal of a perioperative pathway. Cureus 2018; 10: e2072.

Meyer S, McLaughlin VV, Seyfarth HJ, et al. Outcomes of noncardiac, nonobstetric surgery in patients with PAH: an international prospective survey. Eur Respir J 2013; 41: 1302-1307.

Kaw R, Pasupuleti V, Deshpande A, et al. Pulmonary hypertension: an important predictor of outcomes in patients undergoing non-cardiac surgery. Respir Med 2011; 105: 619-624.

Ramakrishna G, Sprung J, Ravi BS, et al. Impact of pulmonary hypertension on the outcomes of noncardiac surgery: predictors of perioperative morbidity and mortality. J Am Coll Cardiol 2005; 45: 1691-1699.

Tonelli AR, Minai OA. Saudi guidelines on the diagnosis and treatment of pulmonary hypertension: perioperative management in patients with pulmonary hypertension. Ann Thorac Med 2014; 9: Suppl. 1 , S98-S107.

Minai OA, Venkateshiah SB, Arroliga AC. Surgical intervention in patients with moderate to severe pulmonary arterial hypertension. Conn Med 2006; 70: 239-243.

Lai HC, Lai HC, Wang KY, et al. Severe pulmonary hypertension complicates postoperative outcome of non-cardiac surgery. Br J Anaesth 2007; 99: 184-190.

Memtsoudis SG, Ma Y, Chiu YL, et al. Perioperative mortality in patients with pulmonary hypertension undergoing major joint replacement. Anesth Analg 2010; 111: 1110-1116.

Seyfarth HJ, Wirtz H, Gille J, et al. Management und postoperatives Überleben bei chirurgischen Eingriffen an Patienten mit schwerer pulmonaler Hypertonie-etrospektive Analyse eines Zentrums [Management and outcome of surgery in patients with severe pulmonary hypertension-a single-center experience]. Pneumologie 2016; 70: 117-122.

Smilowitz NR, Gupta N, Ramakrishna H, et al. Perioperative major adverse cardiovascular and cerebrovascular events associated with noncardiac surgery. JAMA Cardiol 2017; 2: 181-187.

Deljou A, Sabov M, Kane GC, et al. Outcomes after noncardiac surgery for patients with pulmonary hypertension: a historical cohort study. J Cardiothorac Vasc Anesth 2020; 34: 1506-1513.

Hargrave J. Con: preinduction pulmonary artery catheter placement is advisable in patients with right ventricular dysfunction secondary to severe pulmonary hypertension. J Cardiothorac Vasc Anesth 2017; 31 : 1514-1518.

Ventetuolo CE, Klinger JR. Management of acute right ventricular failure in the intensive care unit. Ann Am Thorac Soc 2014; 11: 811-822. 
Boucly A, Cottin V, Nunes $\mathrm{H}$, et al. Management and long-term outcomes of sarcoidosis-associated pulmonary hypertension. Eur Respir J 2017; 50: 1700465.

Sugawara $\mathrm{Y}$, Mizuno $\mathrm{Y}$, Oku S, et al. Effects of vasopressin during a pulmonary hypertensive crisis induced by acute hypoxia in a rat model of pulmonary hypertension. Br J Anaesth 2019; 122: 437-447.

Nowroozpoor A, Malekmohammad M, Seyyedi SR, et al. Pulmonary hypertension in intensive care units: an updated review. Tanaffos 2019; 18: 180-207.

Kerbaul F, Rondelet B, Motte S, et al. Effects of norepinephrine and dobutamine on pressure load-induced right ventricular failure. Crit Care Med 2004; 32: 1035-1040.

Nielsen DV, Torp-Pedersen C, Skals RK, et al. Intraoperative milrinone versus dobutamine in cardiac surgery patients: a retrospective cohort study on mortality. Crit Care 2018; 22: 51.

Ishihara S, Gayat E, Sato N, et al. Similar hemodynamic decongestion with vasodilators and inotropes: systematic review, meta-analysis, and meta-regression of 35 studies on acute heart failure. Clin Res Cardiol 2016; 105: 971-980.

Bednarczyk J, Strumpher J, Jacobsohn E. Inhaled milrinone for pulmonary hypertension in high-risk cardiac surgery: silver bullet or just part of a broader management strategy? Can J Anaesth 2016; 63: 1122-1127.

Rong LQ, Rahouma M, Abouarab A, et al. Intravenous and inhaled milrinone in adult cardiac surgery patients: a pairwise and network meta-analysis. J Cardiothorac Vasc Anesth 2019; 33: 663-673.

Fox DL, Stream AR, Bull T. Perioperative management of the patient with pulmonary hypertension. Semin Cardiothorac Vasc Anesth 2014; 18: 310-318.

Fredholm M, Jörgensen K, Houltz E, et al. Levosimendan or milrinone for right ventricular inotropic treatment?-A secondary analysis of a randomized trial. Acta Anaesthesiol Scand 2020; 64: 193-201.

Hansen MS, Andersen A, Nielsen-Kudsk JE. Levosimendan in pulmonary hypertension and right heart failure. Pulm Circ 2018; 8: 2045894018790905.

Seo JS SK, Kim SH. Perioperative anesthetic considerations in patients with pulmonary hypertension undergoing non-cardiac and non-obstretric surgeries. Med Biol Sci Eng 2019; 2: 31-39.

Villanueva DLE, Agustin RD, Llanes EJ. Pre-operative sildenafil for patients with pulmonary hypertension undergoing mitral valve surgery: a systematic review and meta-analysis. Cardiol Res 2019; 10: 369-377.

Bermejo J, Yotti R, García-Orta R, et al. Sildenafil for improving outcomes in patients with corrected valvular heart disease and persistent pulmonary hypertension: a multicenter, double-blind, randomized clinical trial. Eur Heart J 2018; 39: 1255-1264.

Yang El. Perioperative management of patients with pulmonary hypertension for non-cardiac surgery. Curr Rheumatol Rep 2015; 17: 15.

Tartavoulle T, Bonanno LS, Hall S. Perioperative considerations for patients diagnosed with pulmonary hypertension undergoing noncardiac surgery. J Perianesth Nurs 2019; 34: 240-249.

McGlothlin D, Ivascu N, Heerdt PM. Anesthesia and pulmonary hypertension. Prog Cardiovasc Dis 2012; 55 199-217.

Minai OA, Yared JP, Kaw R, et al. Perioperative risk and management in patients with pulmonary hypertension. Chest 2013; 144: 329-340.

Rudski LG, Lai WW, Afilalo J, et al. Guidelines for the echocardiographic assessment of the right heart in adults: a report from the American Society of Echocardiography endorsed by the European Association of Echocardiography, a registered branch of the European Society of Cardiology, and the Canadian Society of Echocardiography. J Am Soc Echocardiogr 2010; 23: 685-713.

Augoustides JG, Culp K, Smith S. Rebound pulmonary hypertension and cardiogenic shock after withdrawal of inhaled prostacyclin. Anesthesiology 2004; 100: 1023-1025.

Thunberg CA, Morozowich ST, Ramakrishna H. Inhaled therapy for the management of perioperative pulmonary hypertension. Ann Card Anaesth 2015; 18: 394-402.

Cheng JW, Tonelli AR, Pettersson G, et al. Pharmacologic management of perioperative pulmonary hypertension. J Cardiovasc Pharmacol 2014; 63: 375-384.

Wang T, Lu J, Li Q, et al. Rapid titration of intravenous treprostinil to treat severe pulmonary arterial hypertension postpartum: a retrospective observational case series study. Anesth Analg 2019; 129: 1607-1612.

Watanabe $\mathrm{K}$, Ito $\mathrm{N}$, Ohata $\mathrm{T}$, et al. Preoperative balloon pulmonary angioplasty enabled noncardiac surgery of a patient with chronic thromboembolic pulmonary hypertension (CTEPH): a case report. Medicine 2019; 98: e14807.

8 Ota T, Kawai K, Niihata T, et al. Preoperative balloon pulmonary angioplasty for chronic thromboembolic pulmonary hypertension led to successful anesthetic management for total hysterectomy under general anesthesia: a case report. JA Clin Rep 2020; 6: 55.

Diaz-Gomez JL, Ripoll JG, Mira-Avendano I, et al. Multidisciplinary perioperative management of pulmonary arterial hypertension in patients undergoing noncardiac surgery. South Med J 2018; 111: 64-73.

Blaise G, Langleben D, Hubert B. Pulmonary arterial hypertension: pathophysiology and anesthetic approach. Anesthesiology 2003; 99: 1415-1432. 
71 Saugel B, Reuter DA. Perioperative goal-directed therapy using invasive uncalibrated pulse contour analysis. Front Med 2018; 5: 12.

72 Osman D, Ridel C, Ray $\mathrm{P}$, et al. Cardiac filling pressures are not appropriate to predict hemodynamic response to volume challenge. Crit Care Med 2007; 35: 64-68.

73 Brovman EY, Gabriel RA, Dutton RP, et al. Pulmonary artery catheter use during cardiac surgery in the United States, 2010 to 2014. J Cardiothorac Vasc Anesth 2016; 30: 579-584.

74 Tretter JT, Redington AN. The forgotten ventricle? the left ventricle in right-sided congenital heart disease. Circ Cardiovasc Imaging 2018; 11: e007410.

75 Fayad A, Shillcutt S, Meineri M, et al. Comparative effectiveness and harms of intraoperative transesophageal echocardiography in noncardiac surgery: a systematic review. Semin Cardiothorac Vasc Anesth 2018; 22: 122-136.

76 Qi DY, Wang K, Zhang $\mathrm{H}$, et al. Efficacy of intravenous lidocaine versus placebo on attenuating cardiovascular response to laryngoscopy and tracheal intubation: a systematic review of randomized controlled trials. Minerva Anestesiol 2013; 79: 1423-1435.

77 Bedard E, Dimopoulos K, Gatzoulis MA. Has there been any progress made on pregnancy outcomes among women with pulmonary arterial hypertension? Eur Heart J 2009; 30: 256-265.

78 Lai C, Savale L, Boytchev I, et al. Risks and outcomes of gastrointestinal endoscopy with anaesthesia in patients with pulmonary hypertension. Br J Anaesth 2020; 125: e466-e4e8.

79 Villablanca PA, Mohananey D, Ramakrishna H. Comparison of local versus general anesthesia in patients undergoing transcatheter aortic valve replacement: an updated meta-analysis. Catheter Cardiovasc Interv 2018; 92: 1018-1019.

80 Gille J, Seyfarth HJ, Gerlach S, et al. Perioperative anesthesiological management of patients with pulmonary hypertension. Anesthesiol Res Pract 2012; 2012: 356982.

81 Bonnin M, Mercier FJ, Sitbon O, et al. Severe pulmonary hypertension during pregnancy: mode of delivery and anesthetic management of 15 consecutive cases. Anesthesiology 2005; 102: 1133-1137.

82 Turc J, Lamblin A, Klack F, et al. Hypertension pulmonaire et fracture du col fémoral: intérêt de la rachianesthésie continue. [Pulmonary hypertension and femoral neck fracture: interest of continuous spinal anaesthesia]. Ann Fr Anesth Reanim 2012; 31: 557-559.

83 Pilkington SA, Taboada D, Martinez G. Pulmonary hypertension and its management in patients undergoing non-cardiac surgery. Anaesthesia 2015; 70: 56-70.

84 Kaye AD, Hoover JM, Kaye AJ, et al. Morphine, opioids, and the feline pulmonary vascular bed. Acta Anaesthesiol Scand 2008; 52: 931-937.

85 Sivak EL, Davis PJ. Review of the efficacy and safety of remifentanil for the prevention and treatment of pain during and after procedures and surgery. Local Reg Anesth 2010; 3: 35-43.

86 Gooding JM, Dimick AR, Tavakoli M, et al. A physiologic analysis of cardiopulmonary responses to ketamine anesthesia in noncardiac patients. Anesth Analg 1977; 56: 813-816.

87 Tweed WA, Minuck M, Mymin D. Circulatory responses to ketamine anesthesia. Anesthesiology 1972; 37: 613-619.

88 Friesen RH, Twite MD, Nichols CS, et al. Hemodynamic response to ketamine in children with pulmonary hypertension. Paediatr Anaesth 2016; 26: 102-108.

89 Hickey PR, Hansen DD, Cramolini GM, et al. Pulmonary and systemic hemodynamic responses to ketamine in infants with normal and elevated pulmonary vascular resistance. Anesthesiology 1985; 62: 287-293.

90 Williams GD, Philip BM, Chu LF, et al. Ketamine does not increase pulmonary vascular resistance in children with pulmonary hypertension undergoing sevoflurane anesthesia and spontaneous ventilation. Anesth Analg 2007; 105: 1578-1584.

91 Williams GD, Maan H, Ramamoorthy C, et al. Perioperative complications in children with pulmonary hypertension undergoing general anesthesia with ketamine. Paediatr Anaesth 2010; 20: 28-37.

92 Jabre $\mathrm{P}$, Combes $\mathrm{X}$, Lapostolle $\mathrm{F}$, et al. Etomidate versus ketamine for rapid sequence intubation in acutely ill patients: a multicentre randomised controlled trial. Lancet 2009; 374: 293-300.

93 Passot S, Servin F, Pascal J, et al. A comparison of target- and manually controlled infusion propofol and etomidate/desflurane anesthesia in elderly patients undergoing hip fracture surgery. Anesth Analg 2005; 100: 1338-1342.

94 De Castro V, Godet G, Mencia G, et al. Target-controlled infusion for remifentanil in vascular patients improves hemodynamics and decreases remifentanil requirement. Anesth Analg 2003; 96: 33-38.

95 Eissa D, Carton EG, Buggy DJ. Anaesthetic management of patients with severe sepsis. Br J Anaesth 2010; 105: 734-743.

96 Kerbaul F, Rondelet B, Motte S, et al. Isoflurane and desflurane impair right ventricular-pulmonary arterial coupling in dogs. Anesthesiology 2004; 101: 1357-1362.

97 Kerbaul F, Bellezza M, Mekkaoui C, et al. Sevoflurane alters right ventricular performance but not pulmonary vascular resistance in acutely instrumented anesthetized pigs. J Cardiothorac Vasc Anesth 2006; 20: 209-216. 
Blaudszun G, Morel DR. Superiority of desflurane over sevoflurane and isoflurane in the presence of pressure-overload right ventricle hypertrophy in rats. Anesthesiology 2012; 117: 1051-1061.

99 Schulte-Sasse U, Hess W, Tarnow J. Pulmonary vascular responses to nitrous oxide in patients with normal and high pulmonary vascular resistance. Anesthesiology 1982; 57: 9-13.

100 Kellow NH, Scott AD, White SA, et al. Comparison of the effects of propofol and isoflurane anaesthesia on right ventricular function and shunt fraction during thoracic surgery. Br J Anaesth 1995; 75: 578-582.

101 Sprung J, Ogletree-Hughes ML, Moravec CS. The effects of etomidate on the contractility of failing and nonfailing human heart muscle. Anesth Analg 2000; 91: 68-75.

102 Leier CV, Heban PT, Huss P, et al. Comparative systemic and regional hemodynamic effects of dopamine and dobutamine in patients with cardiomyopathic heart failure. Circulation 1978; 58: 466-475.

103 Pagnamenta A, Fesler P, Vandinivit A, et al. Pulmonary vascular effects of dobutamine in experimental pulmonary hypertension. Crit Care Med 2003; 31: 1140-1146.

104 Bradford KK, Deb B, Pearl RG. Combination therapy with inhaled nitric oxide and intravenous dobutamine during pulmonary hypertension in the rabbit. J Cardiovasc Pharmacol 2000; 36: 146-151.

105 Seyfarth HJ, Gille J, Sablotzki A, et al. Perioperative management of patients with severe pulmonary hypertension in major orthopedic surgery: experience-based recommendations. GMS Interdiscip Plast Reconstr Surg DGPW 2015; 4: Doc03.

106 Khanna G SJ. Bone cement and the implications for anaesthesia. Anaesthesia Critical Care Pain 2012; 12: 213-216.

107 Atkinson TM, Giraud GD, Togioka BM, et al. Cardiovascular and ventilatory consequences of laparoscopic surgery. Circulation 2017; 135: 700-710.

108 Sharma VK, Nguyen CC, Crowell MD, et al. A national study of cardiopulmonary unplanned events after GI endoscopy. Gastrointest Endosc 2007; 66: 27-34.

109 Morozowich ST, Murray AW, Ramakrishna H. Pulmonary hypertension in patients for transcatheter and surgical aortic valve replacement: a focus on outcomes and perioperative management. $J$ Cardiothorac Vasc Anesth 2018; 32: 2005-2018.

110 Andersen S, Andersen A, de Man FS, et al. Sympathetic nervous system activation and $\beta$-adrenoceptor blockade in right heart failure. Eur J Heart Fail 2015; 17: 358-366.

111 Futier E, Paugam-Burtz C, Godet T, et al. Effect of early postextubation high-flow nasal cannula vs conventional oxygen therapy on hypoxaemia in patients after major abdominal surgery: a French multicentre randomised controlled trial (OPERA). Intensive Care Med 2016; 42: 1888-1898.

112 Ravesloot MJL, de Raaff CAL, van de Beek MJ, et al. Perioperative care of patients with obstructive sleep apnea undergoing upper airway surgery: a review and consensus recommendations. JAMA Otolaryngol Head Neck Surg 2019; 145: 751-760.

113 American Society of Anesthesiologists Task Force on Perioperative Management of patients with obstructive sleep apnea. Practice guidelines for the perioperative management of patients with obstructive sleep apnea: an updated report by the American Society of Anesthesiologists Task Force on Perioperative Management of patients with obstructive sleep apnea. Anesthesiology 2014; 120: 268-286.

114 Shah R, Agarwal AK. Anemia associated with chronic heart failure: current concepts. Clin Interv Aging 2013; 8: 111-122.

115 Bandyopadhyay D, Bajaj NS, Zein J, et al. Outcomes of $\beta$-blocker use in pulmonary arterial hypertension: a propensity-matched analysis. Eur Respir J 2015; 46: 750-760. 